\title{
Measurement of Antioxidant Effects on the Auto- oxidation Kinetics of Methyl Oleate-Methyl Laurate Blend as a Surrogate Biodiesel System
}

\author{
Tjokorde Walmiki Samadhi ${ }^{*}$, Toshihiro Hirotsu², Shinichi Goto ${ }^{2}$ \\ ${ }^{1}$ Chemical Engineering Program, Faculty of Industrial Technology, Bandung Institute of \\ Technology, Jln. Ganesha 10, Bandung 40132, Indonesia \\ ${ }^{2}$ Research Center for New Fuels and Vehicle Technology, National Institute of Advanced Industrial \\ Science and Technology, AIST Tsukuba East, 1-2-1 Namiki, Tsukuba, Ibaraki 8564, Japan
}

Received: $6^{\text {th }}$ July 2016; Revised: $7^{\text {th }}$ December 2016; Accepted: 30th January 2017

\section{Abstract}

This research investigates the feasibility of methyl oleate-methyl laurate blend as a surrogate biodiesel system which represents jatropha-coconut oil biodiesel, a potentially suitable formulation for tropical climate, to quantify the efficacy of antioxidant additives in terms of their kinetic parameters. This blend was tested by the Rancimat EN14112 standard method. The Rancimat tests results were used to determine the primary oxidation induction period (OIP) and first-order rate constants and activation energies. Addition of $\mathrm{BHT}$ and Ecotive ${ }^{\mathrm{TM}}$ antioxidants reduces the rate constants $\left(k, \mathrm{~h}^{-1}\right)$ between 15 to 90\% in the 50-200 ppm dose range, with Ecotive ${ }^{\mathrm{TM}}$ producing significantly lower $k$ values. Higher dose reduces the rate constant, while oleate/laurate ratio produces no significant impact. Antioxidants increase the oxidation activation energy $(E a, \mathrm{~kJ} / \mathrm{mol})$ by 180 to almost $400 \%$ relative to the nonantioxidant value of $27.0 \mathrm{~kJ} / \mathrm{mol}$. Ecotive ${ }^{\mathrm{TM}}$ exhibits lower $E a$, implying that its higher efficacy stems from a better steric hindrance as apparent from its higher pre-exponential factors. The ability to quantify oxidation kinetic parameters is indicative of the usefulness of methyl oleate-laurate pure FAME blend as a biodiesel surrogate offering better measurement accuracy due to the absence of pre-existing antioxidants in the test samples. Copyright (C) 2017 BCREC GROUP. All rights reserved

Keywords: Antioxidant; Biodiesel; Oxidation kinetics; Rancimat

How to Cite: Samadhi, T.W., Hirotsu, T., Goto, S. (2017). Measurement of Antioxidant Effects on the Auto-oxidation Kinetics of Methyl Oleate-Methyl Laurate Blend as a Surrogate Biodiesel System. Bulletin of Chemical Reaction Engineering \& Catalysis, 12 (2): 157-166 (doi:10.9767/bcrec.12.2.861.157166)

Permalink/DOI: http://dx.doi.org/10.9767/bcrec.12.2.861.157-166

\section{Introduction}

Global warming is a major global environmental issue that is attributed mainly to the anthropogenic emission of greenhouse gases (GHG), primarily carbon dioxide, methane, nitrous oxide, and fluorinated gases [1]. At the

* Corresponding Author.

E-mail: twsamadhi@che.itb.ac.id

Telp.: +62-22-2500989, Fax.: +62-22-2501438 year 2000 global emission rates, these gases are forecasted by the IPCC (International Panel for Climate Change) to cause global temperature increase between 1.1-6.4 ${ }^{\circ} \mathrm{C}$ and sea level increase between 7-23 inches by the year 2100 [2]. IPCC has also stipulated that GHG emissions must be reduced to $50-85 \%$ of the year 2000 rate by 2050 in order to reduce the global temperature rise to an acceptable 2.0-2.4 ${ }^{\circ} \mathrm{C}$ [2]. Of all GHG species, $\mathrm{CO}_{2}$ by far accounts for the largest portion of the global GHG emis- 
sion. In 2012, global $\mathrm{CO}_{2}$ emission rate reached 35 billion metric tons per year and is projected to reach 41 billion MTPY by 2020 unless effective emission reduction measures are taken throughout the world [3].

Transportation is the second largest source of anthropogenic GHG emission, contributing to approximately $22 \%$ of the global $\mathrm{CO}_{2}$ emission [4]. Of particular significance in managing emission from the transportation sector is the vast population of automotive diesel engines. Diesel engines offer lower operating costs, higher fuel efficiency, and higher durability than their gasoline counterparts. Naturally, diesel engines are the power plant of choice for commercial and heavy duty on-road and offroad applications. In spite of their advantages, diesel engines suffer from higher particulate (the so-called 'black carbon' emission) and $\mathrm{NO}_{\mathrm{x}}$ emissions compared to gasoline engines.

Biodiesel is a generic term for fatty acid methyl esters (FAMEs) derived from animal and plant oils and fats. Compared to petroleum diesel, biodiesel contains more oxygen atoms and lower carbon number. While inevitably resulting in a minor penalty in heating value the higher oxygen content generally results in a cleaner burning fuel compared to petroleum diesel. In one study, $20 \%$ substitution of petroleum diesel by biodiesel reduces black carbon emission by $10.1 \%$ and residual hydrocarbon emission by $21.1 \%$. The $\mathrm{NO}_{\mathrm{x}}$ emission is slightly increased by $2 \%$, while $\mathrm{CO}_{2}$ emission is virtually unchanged. The $\mathrm{CO}_{2}$ emission reduc- tion by biodiesel stems not from its direct emission rates, but from the renewability of the fuel source compared to petroleum [5].

A key problem that is unique to biodiesel is its tendency to undergo auto-oxidation during storage and transportation. The classical theory on FAME auto-oxidation describes the degradation as a two-step process. The primary oxidation stage is described as a chain reaction (see Figure 1). The chain initiation step involves the dehydrogenation of methylene groups, for which allylic and bis-allylic methylene groups are particularly reactive (with re-lative order of reaction rate of bis-allylic $>$ allylic $>>$ saturated groups). This dehydrogenation forms alkyl radicals, which in the presence of diatomic oxygen react extremely rapidly to form alkyl peroxide radicals in the chain propagation step. The peroxide radicals subsequently dehydrogenate fatty ester molecules to form more alkyl radicals and hydroperoxides / organic acids at a slower rate. Reactions amongst the free radicals to yield stable products constitute the termination step [6].

The hydroperoxide ( $\mathrm{ROOH})$ concentration remains low during the initial stages of primary oxidation. After a certain period has passed, the concentration of peroxy radicals has increased to a sufficiently high level such that the $\mathrm{ROOH}$ concentration increases rapidly. This period is termed the oxidation induction period (OIP), and is a measure of the resistance of biodiesel to auto-oxidation.

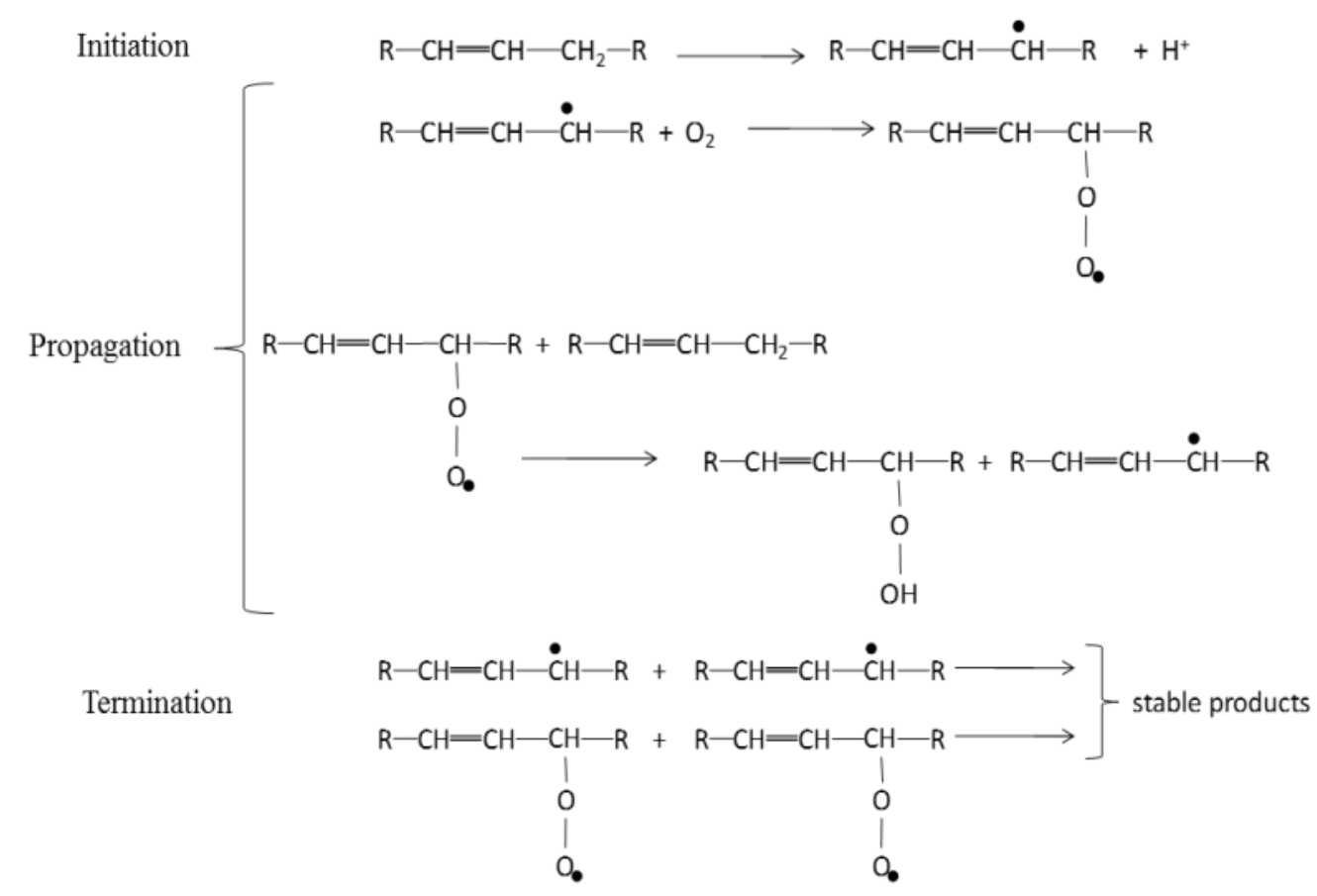

Figure 1. Chain reaction mechanism of the FAME primary oxidation stage 
Much more complex hydroperoxide decomposition reactions occur in the secondary oxidation stage, which include dehydration, cyclization, radical substitution, cracking, dimerization, and more. These reactions result in a wide spectrum of products, including monomeric (keto, epoxy, di- and trihydroxy compounds, dihydroperoxides, etc.), oligomeric species which include dimers and trimers linked via peroxy or ether groups, and short-chain species [7]. Formation of oligomeric and short-chain species increase the viscosity of the biodiesel, resulting in poor cold flow behavior and increased filter and nozzle plugging tendency [8]. The secondary oxidation stage is also associated with the formation of shorter-chain fatty acids, which increases biodiesel acidity, and hence its corrosiveness [9].

Various extraneous factors to which the biodiesel is exposed during storage and transportation may accelerate its auto-oxidation. These include temperature, moisture, and ambient air [10]. Presence of certain metals (e.g. copper) has also been argued as accelerant for the autooxidation, although with some degree of uncertainty [9]. Conversely, the oxidation stability of biodiesel may be improved by the addition of antioxidants. A pioneering work in the application of antioxidants for biodiesel was described by du Plessis and co-workers [11]. These authors have identified the oxidation retardation effect of phenolic compounds (tert-butylhydroxyquinone / TBHQ) on sunflower oil methyl and ethyl esters. By using the pressurized differential scanning calorimetry (P-DSC) technique in non-isothermal mode, Dunn [12] reported an increase in oxidation onset temperature of soybean oil methyl ester by adding synthetic and natural antioxidants. Synthetic antioxidants used by this author were tertbutyl-hydroxyquinone (TBHQ), 3-tert-butyl-4hydroxyanisole (BHA), 2,6-di-tert-butyl-4methyl phenol or butyl hydroxy toluene (BHT), and n-propyl gallate $(\operatorname{PrG})$. For the natural antioxidant, $a$-tocopherol was used.

Mittelbach and Schober [13] employed the Rancimat method to compare the effectiveness of synthetic antioxidants (TBHQ, pyrogallol, npropyl gallate, BHA, and BHT) and tocopherols in improving the oxidation stability of several types of biodiesel. Synthetic antioxidants were found to be more effective than natural antioxidants. The generally higher effectiveness of synthetic antioxidants was also observed by Liang and co-workers [14], who studied the effect of antioxidants on crude and distilled palm oil methyl ester. Synthetic antioxidants required only $1 / 17$ of the dose of natural antioxidants to pass the EN 14214 minimum OIP standard of 6 hours at $110{ }^{\circ} \mathrm{C}$.

The presence of naturally pre-existing antioxidants (such as tocopherols and carotene) in vegetable oils used to synthesize biodiesel results in a wide variation of measured OIP values, even for samples with similar fatty acid compositions [15]. As the observation reported by Liang and co-workers [14] clearly exemplifies, naturally occurring antioxidants in nondistilled palm oil biodiesel produce an OIP of more than 25 hours, compared to only 2.5 hours OIP produced when the palm biodiesel is distilled, effectively removing the natural antioxidants. Thus, the measurement of antioxidant efficacy is prone to interferences from preexisting, naturally existing antioxidants in the biodiesel itself.

Biodiesel surrogates are blends of FAMEs of know purities and compositions which are formulated to mimic certain physico-chemical characteristics of true biodiesel. While surrogates have been quite extensively used to study biodiesel combustion characteristics (see, for example the works by Herbinet and co-workers [16], and Tao and Lin [17]), their application in the study of auto-oxidation is at best scarce. Being free of pre-existing antioxidants, surrogates may arguably serve as a better matrix compared to true biodiesel in auto-oxidation tests aimed at measuring the intrinsic performance of antioxidants.

This paper discusses the measurement of oxidation kinetics of methyl oleate-methyl laurate blend system as a surrogate jatrophacoconut biodiesel system in the presence of antioxidant additives, with a specific target of quantifying the effect of antioxidants in terms of kinetic parameters of the primary autooxidation phase. Selection of jatropha and coconut as the blend components is based on the nature of jatropha as non-edible oil, thus avoiding competitive consumption from the food sector, and on the high auto-oxidation resistance of coconut biodiesel which is attributed to its lack of unsaturated carbon-carbon bonds. Comparison shall be made with kinetic measurement results obtained without antioxidants to highlight the magnitude of efficacy of the antioxidants, and to gain a more comprehensive insight on the role of antioxidants from the reaction kinetics point of view. To the best knowledge of the authors, such use of biodiesel surrogate to measure the OIP performance of antioxidants has never been published to date.

The efficacy of antioxidants in this work is quantified by its first-order kinetic parameters, i.e. rate constant and activation energy. Com- 
putation of these parameters directly utilizes the raw conductivity vs. time data measured by Rancimat. This approach is unique, since most published papers on biodiesel auto-oxidation kinetics transforms the OIP values to derive the integrated form of reaction rate expression, which is subsequently used to determine the kinetic parameters [18,19].

\section{Materials and Methods}

High purity reagent-grade methyl oleate and methyl laurate esters are used (Wako, $>99.0 \%$ ). Since the primary objective of this research is to evaluate the feasibility of using blends of pure FAME as a model biodiesel system in quantifying the kinetic parameters of the auto-oxidation process in the presence of antioxidants, and not to compare the performance of various antioxidants, only two antioxidants are selected for this study. These are butyl hydroxy toluene or BHT (Merck, $\geq 99.0 \%$ ) and Ecotive ${ }^{\mathrm{TM}}$, a proprietary antioxidant.

The major instrument used for this study is the Rancimat Model 743 oxidative stability tester. In the EN14112 standard method, 3-5 grams of the methyl ester sample is contacted with dry air in a heated flask by bubbling. The air bubbles escaping from the sample also strips the volatile short-chain carboxylic acids formed by the primary oxidation stage, which is absorbed by deionized water in a separate absorber flask. The conductivity of the water in the absorber flask increases with an increasing acid concentration in the air transferred from the sample flask. A sharp increase in the conductivity indicates that the oxidation reaction has progressed to the secondary stage, and the time period required to reach this sharp increase in conductivity is recorded as the OIP.

The experimental work in this study involves two parts, namely a preliminary experiment aimed at identifying the appropriate range of antioxidant dose, and a main experiment which measures the kinetic parameters of the oxidation process in the absence and presence of antioxidants. Experimental factors of interest are oleate/laurate volumetric blending ratio, Rancimat oxidation temperature, and antioxidant type and dose. Table 1 compiles all experimental factors and their respective values selected in this study.

Determination of kinetic parameters is based on first-order reaction kinetic treatment of the water absorber conductivity versus time raw data generated by Rancimat. This simple approach is taken on the assumption that the water absorber conductivity is linearly correlated to the concentration of $\mathrm{ROOH}$ produced by the oxidation. Similar approach has also been employed in published literature to determine oxidation rate constants and activation energy of true biodiesels [18,20]. The water absorber conductivity vs. time data are also used to determine the OIP values, although these are not directly related to the kinetic parameters sought after in this work.

\section{Results and Discussion}

\subsection{Determination of antioxidant dose range}

In this preliminary part of the evaluation of antioxidant effects on the oxidation of methyl oleate-laurate blends, the effect of BHT and Ecotive $^{\mathrm{TM}}$ antioxidant concentration is measured by adding selective doses (25, 50, 100, and $200 \mathrm{ppm}$ ) of the antioxidants to pure methyl oleate. The methyl oleate samples which have been added with antioxidants are then tested by the Rancimat instrument at 110 ${ }^{\circ} \mathrm{C}$. Neat methyl oleate is selected for the preliminary experiment since it is naturally the most easily oxidized among the oleate-laurate blending ratio values selected in this research.

The OIP values are determined from the raw conductivity vs. time data in accordance to the 'manual method' described in EN 14214. Figure 2 presents an example of how such determination is undertaken. This particular example refers to the oxidation of methyl oleate with the addition of $100 \mathrm{ppm}$ BHT. Tangent lines are drawn along the linear regions with low slope (representing the initial stages of the primary oxidation phase, where the produced acid concentration is still low) and that with

Table 1. Experimental factors and levels

\begin{tabular}{ll}
\hline Factors & Values \\
\hline Oleate/laurate volumetric ratio & $40 / 60,60 / 40,80 / 20,100 / 0$ \\
Oxidation temperature, ${ }^{\circ} \mathrm{C}$ & $90,100,100$ \\
Antioxidant type & BHT, Ecotive ${ }^{\mathrm{TM}}$ \\
Antioxidant dose, ppm & $0,50,200$ \\
\hline
\end{tabular}


high slope (the earlier stages of the secondary oxidation phase). These tangent lines are extended, and the point at which they intersect is taken as the OIP.

Table 2 summarizes the OIP values obtained by the Rancimat method at the selected antioxidant dose levels. The OIP values vary linearly with the antioxidant dose level. For pure methyl oleate, OIP values obtained by adding Ecotive ${ }^{\mathrm{TM}}$ are 4-5 times longer than those obtained by using BHT. At a dose of up to $200 \mathrm{ppm}$, BHT fails to produce OIP which passes the EN minimum value of 6.0 hours, while Ecotive ${ }^{\mathrm{TM}}$ is able to delay the onset of methyl oleate oxidation to more than 6.0 hours at a dose of $50 \mathrm{ppm}$. Based on these results, and to obtain a more direct comparison between BHT and Ecotive ${ }^{\mathrm{TM}}$, the low and high doses for the subsequent main experiment are set at 50 and $200 \mathrm{ppm}$ respectively for both antioxidants.

It should be reiterated here that the objective of this research is not to find the optimum antioxidant type and dose, but rather to evaluate the impact of antioxidants on the kinetic

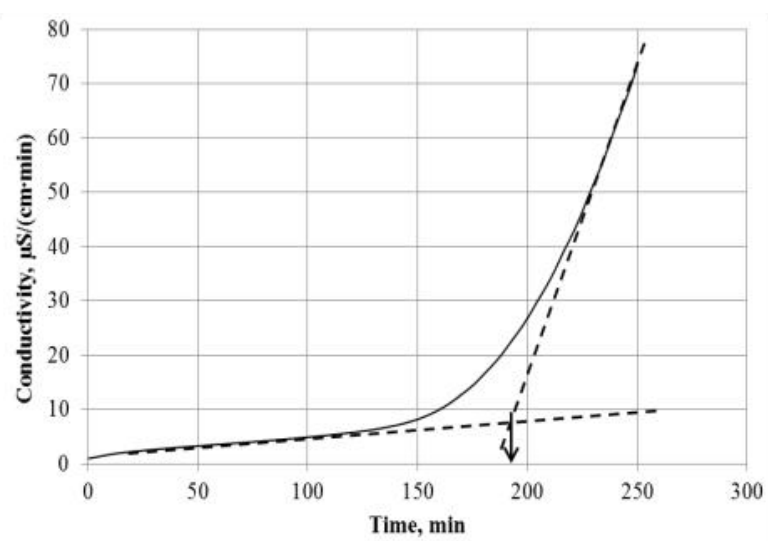

Figure 2. Water absorber conductivity raw data of the oxidation of methyl oleate at $110{ }^{\circ} \mathrm{C}$ with the addition of $100 \mathrm{ppm}$ BHT, indicating the determination of OIP using the tangent intersection method

Table 2. Methyl oleate rancimat OIP at varying antioxidant doses at $110^{\circ} \mathrm{C}$

\begin{tabular}{lll}
\hline \multirow{2}{*}{ Antioxidant dose, ppm } & \multicolumn{2}{c}{ Rancimat OIP, hrs } \\
\cline { 2 - 3 } & BHT & Ecotive \\
\hline 0 & 0.68 & 0.68 \\
25 & 1.40 & 5.70 \\
50 & 2.08 & 9.50 \\
100 & 3.22 & 15.7 \\
200 & 5.67 & 29.0 \\
\hline
\end{tabular}

parameters of the primary oxidation stage of biodiesel. The choice of low and high antioxidant doses of 50 and $200 \mathrm{ppm}$, respectively, is aimed at producing sufficient difference in the IP response values, while avoiding an excessively long IP values which would tend to decrease the precision of oxidative stability measurements.

\subsection{Primary oxidation kinetic parameters measurement}

Measurement of the primary auto-oxidation kinetic parameters is undertaken through a series of Rancimat oxidation tests with experimental factors set according to Table 1. Fundamentally, the intrinsic oxidative stability of pure methyl esters is determined by the number of unsaturated carbon-carbon bonds in the molecules. This premise leads to the description of oxidation propensity in terms of structural parameters that expresses the degree of bond saturation (or unsaturation) of the methyl esters [21]. One such parameter is the degree of unsaturation (DU) proposed by Ramos [22], which is calculated from the fatty acid (FA) composition of the biodiesel sample by Equation (1):

$$
D U=X_{F A, u}+2 X_{F A, p u}
$$

where $D U=$ degree of unsaturation (\%); $X_{F A, u}=$ $\%$-mass of mono-unsaturated fatty acids; and $X_{F A, p u}=\%$-mass of polyunsaturated fatty acids.

Table 3 lists the calculated DU values of the methyl oleate-laurate blends used in this work and several neat biodiesel obtained from the literature. Of the considerable wealth of data on jatropha, palm and coconut methyl esters available in the public literature, only those accompanied by their fatty acid composition data can be used for DU calculation by Equation (1) [23-25].

Methyl oleate-laurate blend Rancimat OIP values are plotted against DU in Figure 3. Error bars corresponding to $95 \%$ confidence interval of the average OIP values of each sample are included, computed from three replicate runs. Also included in the figure are several literature OIP values of neat biodiesels listed in Table 3. Excellent repeatability of the methyl oleate-laurate blend OIP measurements was obtained with the Rancimat test, as indicated by the measurement confidence intervals that are much narrower compared to the overall OIP value range. The OIP values of the methyl oleate-laurate blends exhibits a strong linear correlation with the DU parameter. 
Figure 3 very clearly indicate the discrepancy of measured OIP of the surrogate biodiesel and the true, neat biodiesels with equivalent DU values. All of the neat biodiesels exhibit much longer OIP values than pure FAME blends. This observation indicates that the oxidative stability of true biodiesels is determined to a much larger extent by preexisting antioxidants rather than their fatty acid composition. The palm biodiesel OIP data from Frohlich and Schober [24] are of particular interest, since these authors compare the methyl esters produced from crude palm oil and from palm oil which had been treated by activated carbon to remove the naturallyoccurring tocopherols. Despite this adsorption treatment, the OIP of the palm biodiesel was

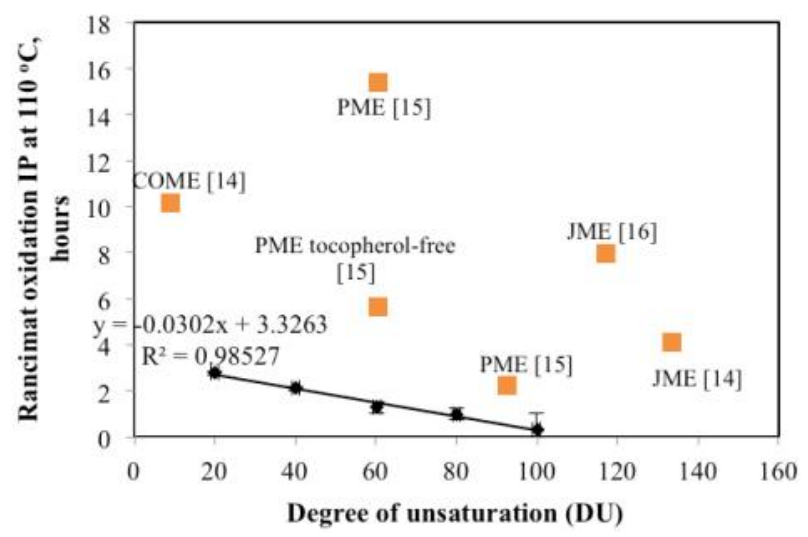

Figure 3. Rancimat OIP measured at $110{ }^{\circ} \mathrm{C}$ of methyl oleate - laurat blends and several neat biodiesels as a function of the degree of unsaturation still significantly higher than the corresponding methyl oleate-laurate blend (at a DU of approximately $60 \%$ ), suggesting an incomplete tocopherol removal or the presence of other antioxidant species not removed by the activated carbon adsorbent. It is therefore clear that the quantification of antioxidant efficacy using true biodiesel is extremely prone to preexisting antioxidants.

By assuming that the primary oxidation stage follows first-order kinetics, rate constants may be determined by computing the slope of $\ln$ (conductivity) vs. time plots. Figure 4 presents first-order plots of the oxidation of methyl oleate-laurate blends at $90{ }^{\circ} \mathrm{C}$ as an example of the kinetic data treatment results. After an initial warm-up period which lasts for approximately 15 minutes, the curves in Figure 2 exhibit a linear behavior in accordance with first-order kinetics. Indeed, such firstorder kinetic behavior is also observed by $\mathrm{Na}$ katani and co-workers [26]. The rate constants of the primary oxidation stage were determined simply by taking the slope of the $\ln$ (Conductivity) vs. time curves in the linear regions, and are compiled in Table 4.

Treatment of Rancimat data for methyl oleate-laurate oxidation with antioxidants is analogous to that of the experiments without using antioxidants. Figure 5 presents the firstorder plots for the oxidation at $100{ }^{\circ} \mathrm{C}$ with the addition of $50 \mathrm{ppm}$ BHT as an example. Comparison of the curves in Figures 4 and 5 confirms that the oxidation of methyl oleatelaurate blends in the presence of antioxidants

Table 3. Calculated degree of unsaturation (DU) of several types of FAME

\begin{tabular}{ccc}
\hline Methyl ester / biodiesel samples & $\begin{array}{c}\text { Degree of unsaturation } \\
\text { (DU) }\end{array}$ & Reference \\
\hline Methyl oleate-methyl laurate blends: & & \\
\hline $20 / 80$ & 20.08 & This work \\
$40 / 60$ & 40.13 & This work \\
$60 / 40$ & 60.13 & This work \\
$80 / 20$ & 80.08 & This work \\
$100 / 0$ & 100.00 & This work \\
\hline Neat biodiesels: & & {$[23]$} \\
Coconut biodiesel & 8.81 & {$[23]$} \\
Jatropha biodiesel & 133.35 & {$[23]$} \\
Palm biodiesel & 92.68 & {$[24]$} \\
Palm biodiesel & 60.60 & {$[24]$} \\
Palm biodiesel, natural tocopherols & 60.60 & {$[25]$} \\
removed & 117.11 & \\
Jatropha biodiesel & & \\
\hline
\end{tabular}


also follows first-order kinetics. In a similar manner to the experiments without antioxidants, rate constants of methyl oleate-laurate oxidation in presence of BHT and Ecotive ${ }^{\mathrm{TM}}$ antioxidants are determined from the slope of $\ln ($ Conductivity) vs. time curves. These are also compiled in Table 4.

As the numbers in Table 4, and the curves in Figures 4 and 5 suggest, the rate constant values are not substantially influenced by the oleate/laurate blending ratios while obviously influenced by the initial concentration (or dose) of the antioxidants. This observation supports the underlying concept of oxidation kinetic modeling in the literature, in which the rate of oxidation in presence of antioxidants is associated with the consumption of the antioxidant itself [19]. Experimental runs undertaken at the four blend ratios are thus regarded as repli-

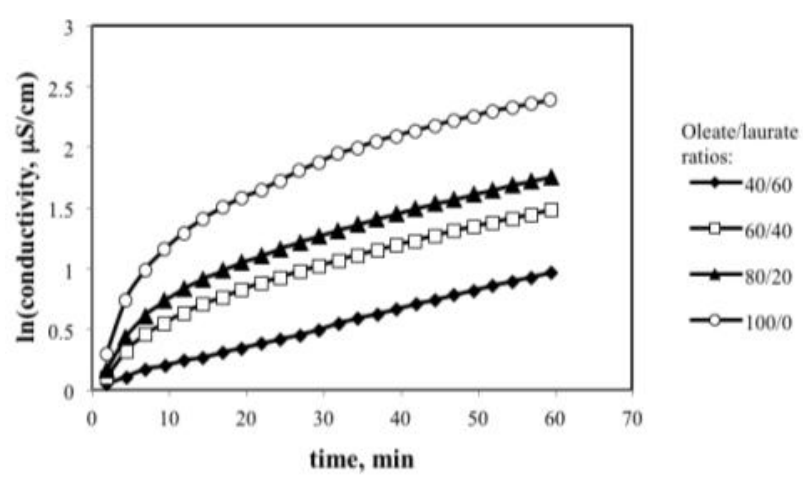

Figure 4. First-order kinetic plot of methyl oleate-laurate blend Rancimat oxidation at $90{ }^{\circ} \mathrm{C}$ cates in computing $95 \%$ confidence intervals of the rate constant at each combination of temperature and antioxidant dose. The averaged rate constants are summarized in Table 5 .

The activation energies of the primary autooxidation with and without antioxidants are then determined using the classical Arrhenius equation:

$$
k=A e^{-E a / R T}
$$

where $k=$ first-order rate constant $\left(\mathrm{h}^{-1}\right) ; A=$ pre-exponential factor $\left(\mathrm{h}^{-1}\right) ; E_{a}=$ activation energy $(\mathrm{kJ} / \mathrm{mol}) ; R=$ ideal gas constant $=8.314$ $\mathrm{kJ} / \mathrm{mol} \mathrm{K}$; and $T=$ reaction temperature $(\mathrm{K})$.

The activation energies are determined from the slope of $\ln (k)$ vs. $1 / T$ plots. The Arrhenius plots encompassing all experimental runs are compiled in Figure 6, which also in-

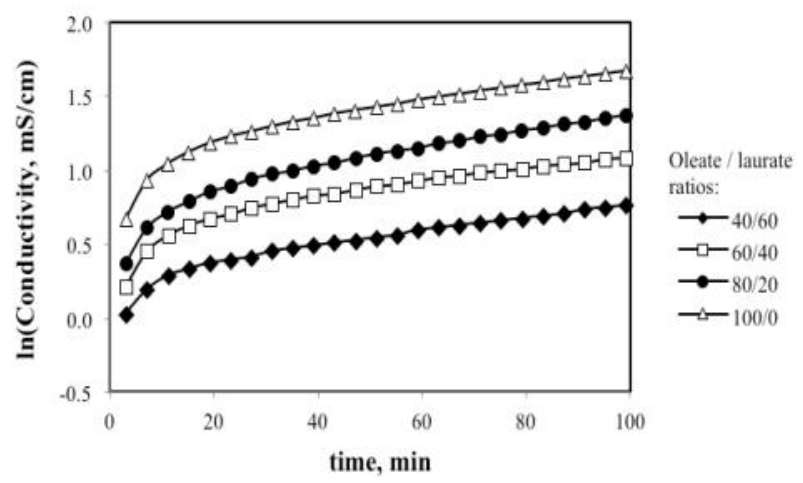

Figure 5. First-order kinetic plot of methyl oleate-laurate blend Rancimat oxidation in the presence of $50 \mathrm{ppm} \mathrm{BHT}$ at $100{ }^{\circ} \mathrm{C}$

Table 4. Methyl laurate - oleate blend oxidation rate constants with and without the addition of antioxidants obtained by the Rancimat method

\begin{tabular}{lllcccc}
\hline \multirow{2}{*}{$\mathrm{T},{ }^{\circ} \mathrm{C}$} & \multirow{2}{*}{$\begin{array}{c}\text { oleate/laurate } \\
\text { blending ratio }\end{array}$} & $\begin{array}{c}\text { No } \\
\text { antioxidant }\end{array}$ & $\begin{array}{c}\mathrm{BHT} \\
50 \mathrm{ppm}\end{array}$ & $\begin{array}{c}\text { BHT } \\
200 \mathrm{ppm}\end{array}$ & $\begin{array}{c}\text { Ecotive }^{\mathrm{TM}} \\
50 \mathrm{ppm}\end{array}$ & $\begin{array}{c}\text { Ecotive }^{\mathrm{TM}} \\
200 \mathrm{ppm}\end{array}$ \\
\hline \multirow{4}{*}{90} & $40 / 60$ & 0.861 & 0.114 & 0.0404 & 0.103 & 0.03096 \\
& $60 / 40$ & 0.762 & 0.12 & 0.0469 & 0.099 & 0.03234 \\
& $80 / 20$ & 0.924 & 0.126 & 0.0402 & 0.108 & 0.02934 \\
& $100 / 0$ & 0.897 & 0.096 & 0.0392 & 0.079 & 0.03222 \\
\hline \multirow{3}{*}{100} & $40 / 60$ & 0.900 & 0.276 & 0.150 & 0.204 & 0.066 \\
& $60 / 40$ & 1.020 & 0.276 & 0.180 & 0.184 & 0.078 \\
& $80 / 20$ & 1.083 & 0.354 & 0.162 & 0.210 & 0.078 \\
& $100 / 0$ & 1.188 & 0.324 & 0.186 & 0.216 & 0.076 \\
\hline \multirow{3}{*}{110} & $40 / 60$ & 1.287 & 1.212 & 0.354 & 0.312 & 0.136 \\
& $60 / 40$ & 1.425 & 1.124 & 0.372 & 0.376 & 0.109 \\
& $80 / 20$ & 1.377 & 1.17 & 0.324 & 0.366 & 0.114 \\
& $100 / 0$ & 1.398 & 1.152 & 0.390 & 0.390 & 0.128 \\
\hline
\end{tabular}


cludes the average rate constant $95 \%$ confidence intervals. The activation energies are summarized in Table 5, also as $95 \%$ confidence intervals. Confidence intervals of the rate constants and activations energies are reasonably narrow, suggesting a good overall measurement precision.

Table 4 and Figure 6 confirm the significant change in kinetic parameters caused by the addition of antioxidants, specifically the increase in activation energy. This is to be expected in the context of antioxidants as reaction inhibitors, which works oppositely to a ca-talyst in

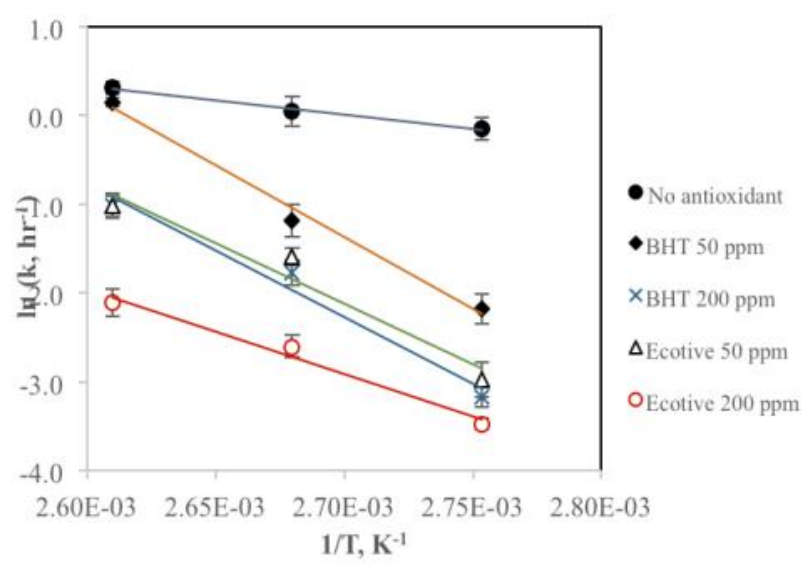

Figure 6. Arrhenius plots of methyl oleate laurate blend oxidation based on first-order reaction kinetics that it provides a new reaction pathway with a higher activation energy compared to the noninhibited pathway. The first-order kinetic analysis of the Rancimat data is also able to quantitatively distinguish the performance of BHT and Ecotive ${ }^{\mathrm{TM}}$. While the latter antioxidant provides lower rate constants and longer OIP, the obtained activation energy is actually lower than that obtained by adding BHT. In this case the pre-exponential factor in the $\mathrm{Ar}$ rhenius equation has a larger impact on the oxidation rate compared to the activation energy, suggesting that Ecotive ${ }^{\mathrm{TM}}$ may provide more steric hindrance to the oxidation reaction relative to $\mathrm{BHT}$.

Increase of antioxidant dose from 50 to 200 ppm does not appear to siginicantly change the activation energy for either BHT or Ecotive ${ }^{\mathrm{TM}}$, as the $95 \%$ confidence intervals in Table 5 suggest. The activation energy of BHT obtained in this work is significantly higher than values reported in the literature. Borsato and coworkers [20] reported an activation energy of $81.72 \mathrm{~kJ} / \mathrm{mol}$ for the oxidation of soybean oil B100 biodiesel with the addition of approximately 1000 ppm BHT. Jain and Sharma [27] reported activation energy of jatropha B100 biodiesel containing BHT that increases linearly with antioxidant dose, based on nonisothermal first-order kinetic data treatment. These authors obtain activation energy values

Table 5. Average rate constants and activation energies of methyl oleate-laurate oxidation

\begin{tabular}{|c|c|c|c|c|c|}
\hline Antioxidant & Dose, ppm & $\mathrm{T},{ }^{\circ} \mathrm{C}$ & $k, \mathrm{~h}^{-1}$ & $E_{a}, \mathrm{~kJ} / \mathrm{mol}$ & $A, \mathrm{~h}^{-1}$ \\
\hline \multirow[t]{3}{*}{ None } & - & 90 & $0.861 \pm 0.113$ & $27.0 \pm 3.5$ & $6.48 \cdot 10^{3}$ \\
\hline & & 100 & $1.048 \pm 0.191$ & & \\
\hline & & 110 & $1.372 \pm 0.095$ & & \\
\hline \multirow[t]{6}{*}{$\overline{\mathrm{BHT}}$} & 50 & 90 & $0.114 \pm 0.021$ & $134.5 \pm 5.8$ & $2.34 \cdot 10^{18}$ \\
\hline & & 100 & $0.308 \pm 0.061$ & & \\
\hline & & 110 & $1.164 \pm 0.059$ & & \\
\hline & 200 & 90 & $0.042 \pm 0.005$ & $125.0 \pm 7.1$ & $4.42 \cdot 10^{16}$ \\
\hline & & 100 & $0.170 \pm 0.026$ & & \\
\hline & & 110 & $0.360 \pm 0.045$ & & \\
\hline \multirow[t]{6}{*}{ Ecotive $^{\mathrm{TM}}$} & 50 & 90 & $0.097 \pm 0.020$ & $76.1 \pm 4.4$ & $8.82 \cdot 10^{9}$ \\
\hline & & 100 & $0.204 \pm 0.022$ & & \\
\hline & & 110 & $0.361 \pm 0.054$ & & \\
\hline & 200 & 90 & $0.031 \pm 0.002$ & $78.7 \pm 4.7$ & $6.94 \cdot 10^{9}$ \\
\hline & & 100 & $0.074 \pm 0.010$ & & \\
\hline & & 110 & $0.122 \pm 0.020$ & & \\
\hline
\end{tabular}


in the 42.96 to $57.06 \mathrm{~kJ} / \mathrm{mol}$ range for $\mathrm{BHT}$ dose of 100 to $600 \mathrm{ppm}$. The difference between values reported in the literature, which are measured by using real biodiesel samples, and those reported in Table 5 highlights once again the risk of intereference from pre-existing antioxidants (and also pro-oxidants) inherently present in real biodiesel in the rigorous measurement of oxidation kinetic parameters.

\section{Conclusions}

The direct treatment of Rancimat conductivity vs. time raw data according to first-order kinetics has been demonstrated to be able to quantify the effect of antioxidants on biodiesel primary oxidation in terms of changes in the rate constants and activation energies. The use of jatropha-coconut biodiesel surrogate in the form of blends of pure methyl oleate and methyl laurate enables the determination of intrinsic kinetic parameters of the auto-oxidation process. It has been confirmed that kinetics of the auto-oxidation in presence of BHT and Ecotive ${ }^{\mathrm{TM}}$ antioxidants refers to the consumption of antioxidants in the primary oxidation phase. Increasing the antioxidant dose from 50 to 200 ppm reduces the rate constants by $63-39 \%$. Oxidation activation energy of the biodiesel surrogate increases 3.6-4.0 times with $\mathrm{BHT}$, and 1.81.9 times with Ecotive ${ }^{\mathrm{TM}}$, confirming the role of antioxidants as reaction inhibitors. To validate the applicability of biodiesel surrogate in the quantification of antioxidant efficacy, similar tests with a wider range of antioxidants is recommended for future studies .

\section{Acknowledgement}

This research was funded and conducted through the 2010 Asia Biomass Researcher Invitation program organized by the New Energy Forum, Japan. Laboratory work for this research was entirely undertaken at the Research Center for New Fuels and Vehicle Technology, National Institute of Advanced Industrial Science and Technology (AIST), Tsukuba East, Japan.

\section{References}

[1] Vijayavenkataraman, S., Iniyan, S., Goic, R. (2012). A Review of Climate Change, Mitigation and Adaptation. Renewable and Sustainable Energy Review, 16: 878-897.

[2] Anonymous. (2007). Climate Change 2007, Synthesis Report, Intergovernmental Panel on Climate Change.
[3] Anonymous. (2012). Turn Down the Heat: Why a 4o Warmer World Must be Avoided, Technical Report, The World Bank.

[4] Anonymous. (2015). $\mathrm{CO}_{2}$ Emissions from Fuel Combustion, Technical Report, International Energy Agency.

[5] Anonymous. (2002). Analysis of Biodiesel Impact on Emissions, Technical Report, United States Environmental Protection Agency.

[6] Frankel, E.N. (1980). Lipid Oxidation. Progress in Lipid Research, 19: 1-22.

[7] Knothe, G. (2007). Some Aspects of Biodiesel Stability. Fuel Processing Technology, 88: 669-677.

[8] Lin, C.Y., Chiu, C.C. (2009). Effects of Oxidation During Long-Term Storage on the Fuel Properties of Palm Oil-Based Biodiesel. Energy and Fuels, 23: 3285-3289.

[9] Canakci, M., Monyem, A., van Gerpen, J. (1999). Accelerated Oxidation Processes in Biodiesel. Transactions of the ASAE, 42: 1565-1572.

[10] Leung, D.Y.C., Koo, B.C.P., Guo, Y. (2006). Degradation of Biodiesel Under Different Storage Conditions. Bioresource Technology, 97: 250-256.

[11] Du Plessis, L.M., de Villiers, J.B.M., van der Walt, W.H. (1985). Stability Studies on Methyl and Ethyl Fatty Acid Esters of Sunflo-werseed Oil. Journal of the American Oil Chemists Society, 62: 748-752.

[12] Dunn, R.O. (2005). Effect of Antioxidants on the Oxidative Stability of Methyl Soyate (Biodiesel). Fuel Processing Technology, 86: 1071-1085.

[13] Schober, S., Mittelbach, M. (2004). The Impact of Antioxidants on Biodiesel Oxidation Stability. European Journal of Lipid Science and Technology, 106: 382-389.

[14] Liang, Y.C., May, C.Y., Foon, C.S., Ngan, M.A., Hock, C.C., Basiron, Y. (2006). The Effect of Natural and Synthetic Antioxidants on the Oxidative Stability of Palm Diesel. Fuel, 85: 867-870.

[15] McCormick, R.L., Ratcliff, M., Moens, L., Lawrence, R. (2007). Several Factors Affecting the Stability of Biodiesel in Standard Accelerated Tests. Fuel Processing Technology, 88: 651-657.

[16] Herbinet, O., Pitz, W.J., Westbrook, C.K. (2008). Detailed Chemical Kinetic Oxidation Mechanism for a Biodiesel Surrogate. Combustion and Flame, 154: 507-528.

[17] Tao, H., Lin, K.C. (B2014). Pathways, Kinetics and Thermochemistry of Methyl-Ester Peroxy Radical Decomposition in the Low- 
Temperature Oxidation of Methyl Butanoate: A Computational Study of a Biodiesel Fuel Surrogate. Combustion and Flame, 161: 22702287.

[18] Xin, J., Imahara, H., Saka, S. (2009). Kinetics on the Oxidation of Biodiesel Stabilized with Antioxidant. Fuel, 88: 282-286.

[19] Chen, Y., Luo, Y. (2011). Oxidation Stability of Biodiesel Derived from Free Fatty Acids Associated with Kinetics of Antioxidants. Fuel Processing Technology, 92: 1387-1393.

[20] Borsato, D., Rafael, J., Cini, D.M., Cremasco, H., Coppo, R.L., Angilelli, K.G., Moreira, I., Cristina, E., Maia, R. (2014). Oxidation Kinetics of Biodiesel from Soybean Mixed with Synthetic Antioxidants BHA, BHT and TBHQ: Determination of Activation Energy. Fuel Processing Technology, 127: 111-116.

[21] Knothe, G. (2002). Structure Indices in FA Chemistry: How Relevant is the Iodine Value? Journal of the American Oil Chemists Society, 79: 847-854.

[22] Ramos, M.J., Fernandez, C.M., Casas, A., Rodriguez, L., Perez, A. (2009). Influence of Fatty Acid Composition of Raw Materials on Biodiesel Properties. Bioresource Technology, 100: 261-268.
[23] Nguyen, M.H. (2009). Effect of Storage Temperature and Antioxidants on Biodiesel Blends. In Asia Biomass Energy Researchers Invitation Program 2008, Collected Papers of Invited Research. Tokyo: New Energy Foundation.

[24] Frohlich, A., Schober, S. (2007). The Influence of Tocopherols on the Oxidation Stability of Methyl Esters. Journal of the American Oil Chemists Society, 84: 579-585.

[25] Wang, R., Hanna, M.A., Zhou, W., Bhadury, P.S., Chen, Q., Song, B., Yang, S. (2011). Production and Selected Fuel Properties of Biodiesel from Promising Non-Edible Oils: Euphorbia Lathyris L., Sapium Sebiferum L. and Jatropha Curcas L. Bioresource Technology, 102: 1194-1199.

[26] Nakatani, N., Tachibana, Y., Kikuzaki, H. (2001) Establishment of a Model Substrate Oil for Antioxidant Activity Assessment by Oil Stability Index Method. Journal of the American Oil Chemists Society, 78: 19-23.

[27] Jain, S., Sharma, M.P. (2012). Application of Thermogravimetric Analysis for Thermal Stability of Jatropha Curcas Biodiesel. Fuel, 93: 252-257. 